\title{
SIGNIFICANT FACTORS AFFECTING THE LIFE CYCLE COST ELEMENTS OF A BUILDING
}

\author{
SAMARANAYAKE. J1 ${ }^{1}$, RAMACHANDRA. T2 \& MADUSHIKA. U. G. D ${ }^{3 *}$ \\ 1, 2, 32 Department of Building Economics, University of Moratuwa, Sri Lanka \\ ${ }^{1}$ samaranayakejanindu@gmail.com, 2thanujar@uom.lk, ${ }^{3}$ dilakshimadushika96@gmail.com
}

\begin{abstract}
Life Cycle Cost (LCC) is a vital decision-making tool for realization of investments. However, it is often challenging to forecast the LCC of a building as it comprises of several elements which are influenced by a range of factors. Hence, this study was carried out to identify the significant factors affecting LCC elements of buildings. Twentyfour (24) factors and ten (10) significant LCC elements identified through a comprehensive literature review were presented to thirty-four (34) experts reached through a purposive sampling method. A questionnaire survey was conducted to collect their views on the significance of those factors while a weighted mean was used to determine the relative significance and thereby identify the level of influence of each factor on the respective LCC elements of buildings. The study concluded that the (6) six most significant factors include: plan shape of the building, size of the building, number of occupants, quality of materials and equipment used, the function of the building, and technology used. Further delving into analysis indicates that all 24 factors influence the construction and maintenance management cost elements at different significant levels. Further, the highest number of elements (8 out of 10), such as construction, utility, administration, services management, cleaning, external work, repair and replacement, and maintenance management are highly influenced by the function of the building. Next to the function, lifetime of the building highly influences the six LCC elements such as construction, utility, administration, services management, repair and replacement, and maintenance management. Similarly, every LCC element is influenced by each factor in different levels and further discussed in this study. Hence, the study recommends that cost practitioners should give due consideration to highly influencing factors to optimise the LCC of a building during its early life cycle phase.
\end{abstract}

Keywords: Building; Factors influencing LCC; LCC; LCC Elements.

\section{Introduction}

Life Cycle Cost (LCC) refers to the assessment of the overall cost of a certain asset over its lifespan (Islam, Jollands, and Setunge, 2015). According to Gluch and Baumann (2004), it is a technique that enables comparative cost assessments over a specified period of time while considering all relevant economic factors in terms of both initial and future operational costs. Past studies revealed that conducting a LCC analysis of buildings serves different purposes. Norris (2001) stated that the LCC is used to compare the cost-effectiveness of alternative investments or business decisions. It can be used as an analysing method that can make decisions for investments (Fuller, 2016). It is a tool that evaluates the time value of money by combining the initial and future expenses (ISO.15686, 2008). Several authors state that LCC analysis is a model of interpreting buildings initial, maintenance, operation, and disposal costs (Korpi and Ala-Risku, 2008).

To this end, the LCC concept plays a major role in investment decision making. However, there are many uncertainties in the accuracy of the LCC analysis (Islam et al., 2015). Since the LCC approach is an investment decision-making tool, the accuracy of LCC analysis is a vital need. The uniqueness of the

*Corresponding author: Tel: +94 771476934 Email Address: dilakshimadushika96@gmail.com

FARU Journal: Volume 08, Issue 1 DOI: http://doi.org/10.4038/faruj.v8i1.95 
buildings and their long life is one reason for the uncertainty of LCC calculations (Sterner, 2002). Besides, price fluctuation of the construction materials is affecting the accuracy of the LCC analysis (Korpi and AlaRisku, 2008). Further, legislative constraints and property values which are changing from time to time caused the potential difference of the estimated LCC and the actual future cost (Kneifel, 2010).

In addition, building size, shape, lifetime, and purpose, number of occupants, quality of material and equipment used, the technology used, the durability of materials and equipment used, location, and legislative constraints are some factors that influence the LCC of buildings (Meng, Wang, \& Currit, 2009; Krstić and Marenjak, 2012; Che-Ghani, Myeda, and Ali, 2016). Further, the degree of influence of those factors towards the LCC analysis could vary in terms of each LCC element. For example, factors such as the function of the building, number of occupants, building shape and size affecting each LCC element of a building (Ali et al., 2010). However, location, physical condition, and climatic condition are mainly affecting the construction cost (Cunningham, 2013). Meanwhile, factors such as service availability and aesthetic appearance are mainly affecting the utility and administration cost (Kerama, 2013).

Despite many researchers investigated the factors that affect the LCC, there seems a limited focus on the degree of significance of those factors towards the LCC elements and analysis. Hence, this study was carried out to identify the significant factors affecting the LCC as well as sub-elements of LCC of a building.

\section{Literature Review}

LCC analysis considers all costs incurred during the lifetime of a building and the first step of LCC analysis is to identify the LCC stages and their cost elements (Aye, Bamford, Charters, and Robinson, 2000; Henn, 2002). According to the past studies, this LCC elements categorisation is varied. Sterner (2002) stated that the LCC includes construction, operation, maintenance, risk, and other costs imposed with a building that can be recurring or non-recurring. Several authors derived the LCC elements as initial, energy cost, operational and maintenance, disposal cost (Wen and Kang, 2001; Morrissey and Horne, 2011; Schade, 2014). The disposal cost can be identified as the residual /salvage value of the building and it covers the cost of demolition (Schade, 2014). Further, according to NRM1, NRM3 and BCIS standards, facilitating works and building works are the main cost elements under the construction cost. Operational cost mainly comprises of utility cost and administrative costs. Service maintenance, decoration, fabric, cleaning, external works, repairs and replacement, and maintenance management are the main cost elements under the maintenance phase.

Islam et al. (2015) indicated that the contribution of construction cost to LCC ranges from $58 \%$ to $88 \%$ while the operation, maintenance and disposal cost contribution vary from $11 \%$ to $34 \%, 2$ to $20 \%, 0$ to $2 \%$, respectively. Similarly, Heralova (2018) stated that the contribution of the disposal cost of a building to its LCC is considerably low. However, Islam et al. (2015) further noted that the cost contribution of each phase depends on the assumptions, boundary of the study and the various factors. Hence, it is important to explore the effects of the factors for LCC planning. According to Islam et al. (2015) and Shabniya (2017), LCC is affected by various factors in pre-construction, construction, and post-construction stages. The authors further stated that the identified factors affecting LCC can be classified under seven main factors: 1) designing of the building, 2) nature of the site, 3) technical factors, 4) tenant factors, 5) function of the building, 6) the number of occupants, and 7) legislative constraints. These factors are further discussed below.

Design of the building: The design of the building entails the characteristics/morphology of the building. It is mainly affecting the construction and maintenance costs of the building (Meng et al., 2009). The main features which character the lifetime of the building, plan shape, size of the building (GFA), wall to floor ratio, circulation space, storey height, the total height of the building, grouping of buildings and ecstatically appearance (Ali et al., 2010; Kerama, 2013; Meng et al., 2009).

Nature of the site: The term nature of site covers a wide range of aspects such as location, physical condition, services availability, resources availability and climate condition of the site (Cunningham, 2013; Kerama, 2013). Physical condition refers to different kinds of site conditions such as sub-surface and geotechnical conditions, environmental and hydrological conditions (Kinlan, 2014). Services availabilities indicate the sewer and stormwater drainage, mains water supply, electricity, telecommunications services while resource availability refers to resources such as products and materials, construction plant, tools and 
equipment, human resources, space and facilities, subcontractors and finance available in a site or nearby (Krstić and Marenjak, 2012). The climate condition of a site can be defined as the condition of the site surroundings such as weather temperature, soil temperature, sunshine, relative humidity, wind direction and speed, rainfall, weather detrimental phenomena, and weather forecast (Zareaian and Zadeh, 2013). Therefore, these factors are affecting the construction cost as well as the maintenance cost (Cunningham, 2013).

Technical factors: The technical factors comprise of technology used, workmanship, quality and durability of materials and equipment used (Kinlan, 2014). These factors are influencing the construction as well as maintenance cost (Kerama, 2013). According to Kinlan (2014), workmanship is the amount of skill that labour or professional has to do a specific work. The author further stated that poor workmanship will increase the cost of maintenance. The quality and the durability of equipment and materials that are used to construct the building are directly linked with the operational, maintenance and construction cost (Bari et al., 2012).

Tenant factors: The expectation of the tenant, use of the property, vandalism by the tenants, delay and failure in reporting problems and accessibility to the property are the tenant factors that affect the LCC of buildings (Cunningham, 2013; Kerama, 2013). However, Che-Ghani et al. (2016) and Meng et al. (2009) indicated that factors like vandalism by the tenants and the accessibility to the property are ignorable.

The function of the building: The function of the building refers to the purpose of the building (Ali et al., 2010). Bari et al. (2012) explained that the building function affects the construction, operational and maintenance cost of a building.

Number of occupants: The number of occupants refers to how many workers or occupants are occupied in the building (Ali et al., 2010). According to Cunningham (2013) and Kerama (2013), this factor affects the construction, operational and maintenance cost of a building.

Legislative constraints: According to Cunningham (2013) and Kerama (2013), legislative constraints include all government's influence on the cost of a building throughout its lifetime, incensement of taxes, government rules and regulations.

A summary of the above identified factors and their relationship with the identified main LCC cost elements of a building through the literature review are presented in Table 1.

As evidenced from Table 1, factors like lifetime and function of the buildings are influencing through life costs of the building while there is a number of factors such as plan shape, size of the building (GFA), wall to floor ratio, location and physical condition of the site are specific to certain life cycle cost elements. Although the above review evidence that the LCC of a building depends on the various factors, there needs. to be an assessment on the level of significance of those factors towards the LCC elements, so that LCC can be optimised effectively by addressing the significant factors.

\begin{tabular}{|c|c|c|c|c|c|c|c|c|c|c|c|}
\hline & Factors & 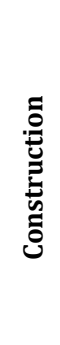 & 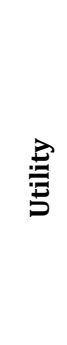 & 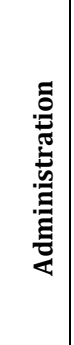 & 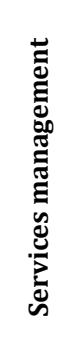 & 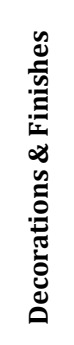 & 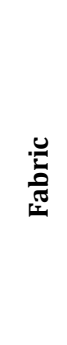 & 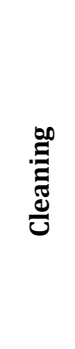 & 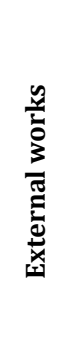 & 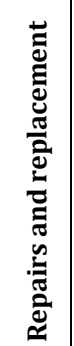 & 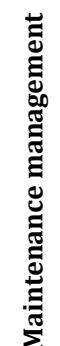 \\
\hline & Design of the building & & & & & & & & & & \\
\hline 1 & Lifetime & $\checkmark$ & $\checkmark$ & $\checkmark$ & $\checkmark$ & $\checkmark$ & $\checkmark$ & $\checkmark$ & $\checkmark$ & $\checkmark$ & $\checkmark$ \\
\hline 2 & Plan shape & $\checkmark$ & & & $\checkmark$ & $\checkmark$ & $\checkmark$ & & $\checkmark$ & $\checkmark$ & $\checkmark$ \\
\hline 3 & $\begin{array}{l}\text { Size of the building } \\
\text { (GFA) }\end{array}$ & $\checkmark$ & $\checkmark$ & & $\checkmark$ & $\checkmark$ & & & $\checkmark$ & $\checkmark$ & $\checkmark$ \\
\hline 4 & Wall to floor ratio & & & & $\checkmark$ & $\checkmark$ & & & & $\checkmark$ & $\checkmark$ \\
\hline
\end{tabular}




\begin{tabular}{|c|c|c|c|c|c|c|c|c|c|c|c|}
\hline 5 & Circulation space & & $\checkmark$ & & $\checkmark$ & $\checkmark$ & & & $\checkmark$ & & \\
\hline 6 & Storey height & $\checkmark$ & $\checkmark$ & & $\checkmark$ & $\checkmark$ & $\checkmark$ & & $\checkmark$ & & \\
\hline 7 & $\begin{array}{l}\text { Total height of the } \\
\text { building }\end{array}$ & $\checkmark$ & & & $\checkmark$ & $\checkmark$ & & & $\checkmark$ & & \\
\hline 8 & Grouping of buildings & & $\checkmark$ & & & $\checkmark$ & & & & $\checkmark$ & $\checkmark$ \\
\hline \multirow[t]{2}{*}{9} & Aesthetic appearance & $\checkmark$ & & & & $\checkmark$ & $\checkmark$ & $\checkmark$ & $\checkmark$ & & \\
\hline & Nature of the site & & & & & & & & & & \\
\hline 10 & Location & $\checkmark$ & $\checkmark$ & & & $\checkmark$ & & & & & \\
\hline 11 & Physical Condition & $\checkmark$ & & & & & & & & & \\
\hline 12 & Services availability & & $\checkmark$ & $\checkmark$ & & & & & & & \\
\hline 13 & Resource availability & & $\checkmark$ & $\checkmark$ & & $\checkmark$ & & $\checkmark$ & & & \\
\hline \multirow[t]{2}{*}{14} & Climate condition & $\checkmark$ & & & $\checkmark$ & $\checkmark$ & $\checkmark$ & & $\checkmark$ & $\checkmark$ & $\checkmark$ \\
\hline & Technical factors & & & & & & & & & & \\
\hline 15 & Technology used & $\checkmark$ & & & $\checkmark$ & $\checkmark$ & & $\checkmark$ & $\checkmark$ & $\checkmark$ & $\checkmark$ \\
\hline 16 & Workmanship & $\checkmark$ & & & $\checkmark$ & $\checkmark$ & & $\checkmark$ & $\checkmark$ & $\checkmark$ & $\checkmark$ \\
\hline 17 & $\begin{array}{l}\text { Quality of materials \& } \\
\text { equipment used }\end{array}$ & $\checkmark$ & & & $\checkmark$ & & & & & $\checkmark$ & $\checkmark$ \\
\hline \multirow[t]{2}{*}{18} & $\begin{array}{l}\text { Durability of materials } \\
\text { \& equipment used }\end{array}$ & $\checkmark$ & & & $\checkmark$ & $\checkmark$ & & & & $\checkmark$ & $\checkmark$ \\
\hline & Tenant factors & & & & & & & & & & \\
\hline 19 & Expectation of tenants & $\checkmark$ & & $\checkmark$ & & $\checkmark$ & $\checkmark$ & $\checkmark$ & $\checkmark$ & $\checkmark$ & $\checkmark$ \\
\hline 20 & Use of the property & & & $\checkmark$ & & & & & & & \\
\hline 21 & $\begin{array}{l}\text { Delay and failure in } \\
\text { reporting problem }\end{array}$ & & & & $\checkmark$ & $\checkmark$ & $\checkmark$ & & & $\checkmark$ & $\checkmark$ \\
\hline 22 & $\begin{array}{l}\text { Function of the } \\
\text { building }\end{array}$ & $\checkmark$ & $\checkmark$ & $\checkmark$ & $\checkmark$ & $\checkmark$ & $\checkmark$ & $\checkmark$ & $\checkmark$ & $\checkmark$ & $\checkmark$ \\
\hline 23 & Number of occupants & & $\checkmark$ & $\checkmark$ & $\checkmark$ & & & & & $\checkmark$ & $\checkmark$ \\
\hline 24 & $\begin{array}{l}\text { Legislative } \\
\text { constraints }\end{array}$ & & & $\checkmark$ & & & & & & & \\
\hline
\end{tabular}

Table 1: Factors influencing LCC elements

Adapted from: (Kerama, 2013, Meng et al., 2009, Bari et al., 2012, Krstić and Marenjak, 2012, Cunningham, 2013, Islam et al., 2015, Che-Ghani et al., 2016, Shabniya, 2017)

\section{Research Methodology}

The study primarily used a quantitative approach where the required data were collected through a questionnaire survey. The review of the literature identified twenty-four (24) factors under seven main factors. A questionnaire prepared incorporating those factors was distributed among thirty-seven (37) professionals selected using a purposive sampling technique. Of the selected sample, thirty-four (34) responded to the survey, yielded a response rate of more than 93\%. The views were collected from specialised professionals such as Engineers, Architects, and Quantity Surveyors who have knowledge and experience about the LCC concept on a Likert scale and analysed using weighted mean average. Out of 34, $32 \%$ of respondents have engaged in LCC based activities while remaining $68 \%$ have not directly experienced the LCC based practices but exposed and familiar with the LCC concept.

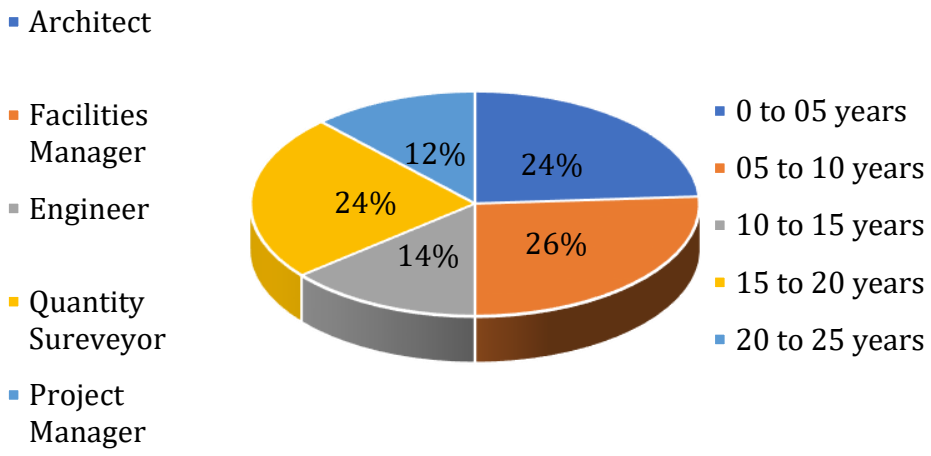

Figure 1: Professional distribution of respondents (left), Years of experience of respondents (right) 
Figure 1 shows the type of participants whom the questionnaire was sent out and their experiences in the construction industry. Out of 34 participants, 29\% were Quantity Surveyors while another 26\% were Engineers. Another 21\% were Facility Managers while an equal number of Architects and Project Managers composed the remaining share of the participants. Of the 34 respondents, the majority (26\%) had 5 to 10 years of experience in construction.

The questionnaire comprised of main two sections: 1) section 1 - the significant factors influencing the LCC of buildings and 2) section 2 - the of influence of each factor on LCC elements.

Initially, respondents were asked to rank the factors which were collected through the literature review on a Likert Scale of 1-5 where 1 refers to 'Not at all influence', 2 - 'Slightly influence', 3 - 'Neutral', 4 - 'influence' and 5 - 'Highly influence'.

To analyse the professionals' views, the weighted mean of each factor was calculated using the following equation.

$$
W M R=\frac{\sum_{i=1}^{5}\left(x_{i} \times f_{i}\right)}{\sum R}
$$

Where: WMR= Weighted Mean Rating for an attribute; $f_{i}=$ Frequency of responses for an attribute, $x_{i}=$ Likert scale for an attribute (ranging 1 to 5 ), $\sum \mathrm{R}=$ Total number of respondents.

Further, the significant level of each factor towards the LCC cost and LCC elements was determined based on the following WMR values:

- $4.75 \leq \mathrm{WMR} \geq 5 \quad$ - Highly Influence

- $\quad 3.50 \leq \mathrm{WMR} \geq 4.75 \quad$ - Influence

- $2.00 \leq \mathrm{WMR} \geq 3.50 \quad$ - Slightly influence

- $\quad \leq \mathrm{WMR} \geq 2.00 \quad$ - Not at all influence

\section{Data Analysis and Findings}

\subsection{FACTORS AFFECTING THE LCC OF BUILDINGS}

Twenty-four (24) factors identified in the literature were presented to professionals and their responses were analysed and presented in Table 2.

\begin{tabular}{|l|c|c|c|}
\hline \multicolumn{1}{|c|}{ Factors } & WMR & $\begin{array}{c}\text { Level of } \\
\text { Influence }\end{array}$ & Rank \\
\hline Plan shape & HI & 1 \\
\hline Size of building (GFA) & 4.00 & HI & 2 \\
\hline Number of occupants & 4.97 & HI & 2 \\
\hline Quality of material and equipment used & 4.94 & HI & 4 \\
\hline Function of the building & 4.94 & HI & 4 \\
\hline Technology used & 4.88 & HI & 6 \\
\hline Physical Condition & 4.88 & HI & 6 \\
\hline Durability of material and equipment used & 4.85 & HI & 8 \\
\hline Lifetime & 4.85 & HI & 8 \\
\hline Location & 4.82 & HI & 10 \\
\hline Workmanship & 4.82 & HI & 10 \\
\hline Legislative constraints & 4.82 & HI & 10 \\
\hline Resource availability & 4.76 & HI & 13 \\
\hline Storey heights & 4.62 & I & 14 \\
\hline Services availability & 4.59 & I & 15 \\
\hline Delay and failure in reporting problem & 4.44 & I & 16 \\
\hline Total height of the building & 4.35 & I & 17 \\
\hline Aesthetic appearance & 4.21 & I & 18 \\
\hline Expectation of tenant & 3.97 & I & 19 \\
\hline
\end{tabular}




\begin{tabular}{|l|c|c|c|}
\hline Grouping of buildings & 3.79 & I & 20 \\
\hline Wall to floor ratio & 3.71 & I & 21 \\
\hline Climate condition & 3.68 & I & 22 \\
\hline Circulation space & 3.65 & I & 23 \\
\hline Use of the property & 3.65 & I & 23 \\
\hline
\end{tabular}

Table 2: Factors affecting the LCC of a building

As shown in Table 2, all 24 factors are affecting the LCC of a building. Of them, building lifetime, plan shape, size of the building (GFA), location and physical condition, resource availability in the site, the technology used, workmanship, quality and durability of materials and equipment used, number of occupants, the function of the building and legislative constraints are highly influencing the LCC than the other factors. These thirteen (13) factors have received a mean score of above 4.75 while the rest of the 11 factors were recorded with a mean value of above 3.50 and below 4.75. Overall, all factors were considered significant in influencing the LCC. Hence, all these factors were considered for further analysis of these factors' influence on each life cycle cost element. The next section presents the degree of their influence on individual elements of LCC.

\subsection{LCC ELEMENTS AND FACTORS INFLUENCING}

Although the above factors influencing the overall LCC, the degree of their influence on each LCC element may vary as those elemental costs are attributed to different phases of the life cycle of a building. Therefore, the WMR of each factor was calculated to determine the influencing level of each factor as per the Likert scale described previously and presented in Table 3 .

\subsubsection{Construction cost}

As seen from Table 3, construction cost is affected by all the twenty-four (24) factors to a varying degree. According to the weighted mean values calculated, fourteen (14 out of 24) factors such as lifetime, plan shape, size of the building (GFA), storey heights, total height of the building, aesthetic appearance, location, physical condition, the technology used, workmanship, quality of material and equipment used, the durability of material and equipment used, the expectation of tenant, and function of the building highly affect the construction cost while wall to floor ratio, circulation space, resource availability, climate condition, and legislative constraints belongs to influence category. According to Table 3, the remaining five (5) factors are slightly influencing the construction cost. All the respondents (100\%) agreed that the size and plan shape of the building directly has an impact on the construction cost of the building. The size of the building has scored the weighted mean value of 5.00, indicated as the highly influencing factor of the construction cost.

\begin{tabular}{|c|c|c|c|c|c|c|c|c|c|c|}
\hline Factors & 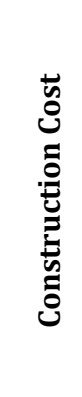 & 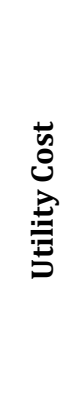 & 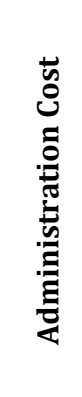 & 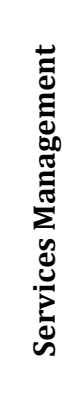 & 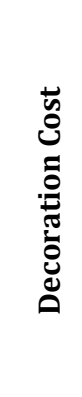 & 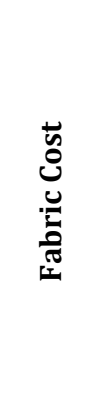 & 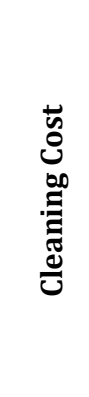 & 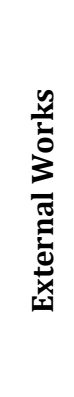 & 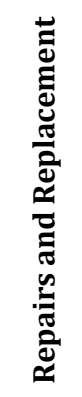 & 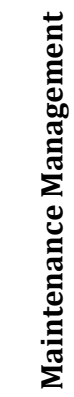 \\
\hline \multicolumn{11}{|l|}{$\begin{array}{l}\text { Design of the } \\
\text { building }\end{array}$} \\
\hline Lifetime & $\mathrm{HI}$ & $\mathrm{HI}$ & $\mathrm{HI}$ & $\mathrm{HI}$ & I & I & SI & I & $\mathrm{HI}$ & $\mathrm{HI}$ \\
\hline Plan shape & $\mathrm{HI}$ & SI & I & $\mathrm{HI}$ & $\mathrm{HI}$ & $\mathrm{HI}$ & $\mathrm{HI}$ & I & I & SI \\
\hline $\begin{array}{l}\text { Size of the building } \\
\text { (GFA) }\end{array}$ & $\mathrm{HI}$ & $\mathrm{HI}$ & NI & HI & SI & I & $\mathrm{HI}$ & NI & I & $\mathrm{HI}$ \\
\hline Wall to floor ratio & I & I & I & I & NI & NI & $\mathrm{NI}$ & NI & I & $\mathrm{HI}$ \\
\hline Circulation space & I & I & I & $\mathrm{HI}$ & $\mathrm{HI}$ & $\mathrm{HI}$ & I & I & I & $\mathrm{HI}$ \\
\hline
\end{tabular}




\begin{tabular}{|c|c|c|c|c|c|c|c|c|c|c|}
\hline Storey heights & $\mathrm{HI}$ & $\mathrm{HI}$ & $\mathrm{NI}$ & $\mathrm{HI}$ & I & $\mathrm{NI}$ & SI & $\mathrm{I}$ & $\mathrm{HI}$ & $\mathrm{HI}$ \\
\hline $\begin{array}{l}\text { Total height of the } \\
\text { building }\end{array}$ & HI & $\mathrm{HI}$ & SI & HI & I & I & I & I & SI & $\mathrm{HI}$ \\
\hline Grouping of buildings & SI & $\mathrm{HI}$ & $\mathrm{I}$ & NI & $\mathrm{I}$ & SI & SI & $\mathrm{I}$ & SI & $\mathrm{I}$ \\
\hline Aesthetic appearance & $\mathrm{HI}$ & NI & $\mathrm{NI}$ & SI & $\mathrm{HI}$ & HI & $\mathrm{HI}$ & I & I & I \\
\hline \multicolumn{11}{|l|}{ Nature of the site } \\
\hline Location & $\mathrm{HI}$ & SI & SI & I & I & SI & $\mathrm{NI}$ & I & NI & I \\
\hline Physical Condition & $\mathrm{HI}$ & $\mathrm{NI}$ & $\mathrm{NI}$ & $\mathrm{I}$ & SI & $\mathrm{NI}$ & NI & $\mathrm{NI}$ & SI & SI \\
\hline Services availability & SI & $\mathrm{HI}$ & $\mathrm{HI}$ & I & I & I & SI & I & I & $\mathrm{HI}$ \\
\hline $\begin{array}{l}\text { Resources } \\
\text { availability }\end{array}$ & I & NI & $\mathrm{HI}$ & SI & NI & I & NI & SI & NI & $\mathrm{HI}$ \\
\hline Climate condition & $\mathrm{I}$ & $\mathrm{NI}$ & $\mathrm{HI}$ & $\mathrm{HI}$ & $\mathrm{HI}$ & $\mathrm{HI}$ & $\mathrm{I}$ & $\mathrm{HI}$ & $\mathrm{I}$ & SI \\
\hline \multicolumn{11}{|l|}{ Technical factors } \\
\hline Technology used & $\mathrm{HI}$ & $\mathrm{I}$ & $\mathrm{NI}$ & $\mathrm{HI}$ & NI & SI & I & SI & $\mathrm{HI}$ & SI \\
\hline Workmanship & $\mathrm{HI}$ & SI & $\mathrm{NI}$ & $\mathrm{HI}$ & $\mathrm{NI}$ & $\mathrm{I}$ & $\mathrm{HI}$ & $\mathrm{I}$ & $\mathrm{HI}$ & I \\
\hline $\begin{array}{l}\text { Quality of material } \\
\text { and equipment used }\end{array}$ & HI & $\mathrm{NI}$ & I & HI & SI & I & I & I & $\mathrm{HI}$ & $\mathrm{HI}$ \\
\hline $\begin{array}{l}\text { Durability of material } \\
\text { and equipment used }\end{array}$ & HI & SI & NI & HI & NI & NI & I & NI & HI & $\mathrm{HI}$ \\
\hline \multicolumn{11}{|l|}{ Tenant factors } \\
\hline Expectation of tenant & $\mathrm{HI}$ & SI & $\mathrm{HI}$ & SI & I & $\mathrm{I}$ & I & $\mathrm{HI}$ & I & I \\
\hline Use of the property & SI & I & $\mathrm{HI}$ & $\mathrm{HI}$ & NI & $\mathrm{HI}$ & NI & SI & SI & $\mathrm{HI}$ \\
\hline $\begin{array}{l}\text { Delay and failure in } \\
\text { reporting problem }\end{array}$ & SI & NI & I & I & NI & NI & I & SI & HI & HI \\
\hline $\begin{array}{l}\text { Number of } \\
\text { Occupants }\end{array}$ & SI & HI & $\mathrm{HI}$ & SI & I & NI & HI & I & HI & HI \\
\hline $\begin{array}{l}\text { Function of the } \\
\text { building }\end{array}$ & HI & HI & $\mathrm{HI}$ & HI & NI & NI & HI & HI & HI & HI \\
\hline $\begin{array}{l}\text { Legislative } \\
\text { constraints }\end{array}$ & I & I & HI & NI & NI & NI & I & $\mathrm{NI}$ & I & SI \\
\hline
\end{tabular}

Table 3: Analysis of factors affecting LCC elements

\subsubsection{Utility cost}

According to the weighted mean analysis, the function of the building is highly affecting the utility cost as scored a mean value of 4.97. The next highly influencing factor is the number of occupants which scored a weighted mean value of 4.91. As shown in Table 3, altogether eight (08) factors are identified as highly affecting the utility cost of a building. There are five (05) factors for both the influence and the slight influence category. There are six (06) factors that scored the mean value below 2.00, hence not influence the utility cost. However, no respondent agreed that the aesthetic appearance has an impact on the utility cost.

\subsubsection{Administration Cost}

Administration cost is mainly affected by the function of the building and the number of occupants which scored a weighted mean value of 4.97 and 4.94, respectively. In addition to the above two factors, seven (07) other factors such as lifetime, services availability, resources availability, climate condition, the expectation of tenant, use of the property, and legislative constraints are in the range of highly influencing the administration cost. No respondent agreed that the physical condition has an impact on administration cost.

\subsubsection{Services Management Cost}

Services management cost is mainly affected by the function of the building which scored a weighted mean value of 4.97. According to the weighted mean values scored, the grouping of the building and legislative 
changes has no impact on services management cost. While thirteen (13) factors; lifetime, plan shape, size of the building (GFA), circulation space, storey heights, total height of the building, climate condition, technology used, workmanship, quality of material and equipment used, the durability of material and equipment used, use of the property, and function of the building highly influence the services management cost, another four (04) such as aesthetic appearance, resources availability, the expectation of tenant, and the number of occupants factors slightly influence the services management cost. From the remaining factors, five (05) factors belong to the influence category by scoring a mean value between $3.50-2.00$.

\subsubsection{Decoration Cost}

Decoration cost is mainly affected by the aesthetic appearance of the building which scored a weighted mean value of 4.97. In addition to the aesthetic appearance, only the four factors including climatic condition, plan shape, circulation space, and the total height of the building highly influence the decoration cost of the building. No respondent agreed to the factors that legislative constraints and function of the building have an impact on the decoration cost.

\subsubsection{Fabric Cost}

All respondents agreed that aesthetical appearance highly influences the fabric cost of the building. As stated in Table 3, there are five (05) factors are highly influencing the fabric cost including an aesthetic appearance with above 4.75 of the weighted mean value. In addition, eight (08) factors such as lifetime, size of the building (GFA), the total height of the building, services availability, resources availability, workmanship, quality of material and equipment used, and expectation of tenant belongs to influence category while three (03) factors such as grouping of buildings, location, and technology used belong to slightly influence category. As per Table 3, the remaining eight (08) factors have no impact on fabric cost as they have scored below 2.00 of the weighted mean value.

\subsubsection{Cleaning Cost}

According to the weighted mean analysis, the function of the building highly influences the cleaning cost as scored a mean value of 4.88. As per Table 3, nineteen (19) factors influence the decoration cost while five (5) factors have a score below 2.00 of mean value and no impact on cleaning cost. Among the influencing factors, six (06) factors including plan shape, aesthetic appearance, number of occupants, size of the building (GFA), function of the building and workmanship highly influence the cleaning cost, while, nine (09) factors such as circulation space, the total height of the building, climate condition, technology used, quality of material and equipment used, the durability of material and equipment used, the expectation of tenant, delay and failure in reporting problem, and legislative constraints belongs to influence category and four (04) factors including lifetime, storey heights, the grouping of buildings, and services availability slightly influence the cleaning cost.

\subsubsection{External work cost}

The climate condition and function of the building highly influence the external work cost with the scored weighted mean value of 4.82. According to Table 3, the expectation of the tenant and function of the building is the other factors that are highly influencing the external work cost with the mean value of 4.79. While twelve (12) factors belong to the influence category, four (04) factors slightly influence the external work cost. Five (05) factors such as the size of the building (GFA), wall to floor ratio, physical condition, the durability of material and equipment used, and legislative constraints have no impact on the external work cost.

\subsubsection{Repairs and Replacement Cost}

According to the weighted mean analysis, the technology used is highly affecting the cleaning cost as scored a mean value of 4.94. The next highly influential factor is workmanship which scored 4.91 of the weighted mean value. According to Table 3, there are nine (09) factors that highly influence the repair and replacement cost including the aforementioned two factors. From the remaining factors, nine (09) factors belong to the influence category and four (04) factors are slightly influencing the repair and replacement cost of a building. Further two (02) factors namely, resources availability and location have no impact on the repair and replacement cost. 


\subsubsection{Maintenance Management Cost}

As shown in Table 3, all the identified factors have an impact on the maintenance management cost of a building. Weighted mean analysis shows that the size of the building and function of the building highly influences the maintenance management cost. Apart from that, eleven (11) factors such as lifetime, wall to floor ratio, circulation space, storey heights, the total height of the building, services availability, resources availability, quality of material and equipment used, the durability of material and equipment used, use of the property, delay and failure in reporting problem highly influence the maintenance management cost. The technology used factor is the least influential factor to the maintenance management cost.

\section{Discussion}

The comprehensive literature review identified the twenty-four (24) factors affecting the LCC of a building and subsequently, the survey results also confirmed that those factors affect the LCC of a building. Of the 24 factors, the analysis shows that the plan shape and size of the building are the top two ranking factors with the 4.75 mean value, highly influencing the LCC of a building. This result is in line with the study of Kerama (2013);

When referring to the effect of each factor on LCC elements, there are some dissimilarities as well as similarities among the literature findings and survey findings. The survey result shows that all nine factors under the designing of the building affect the construction and maintenance management cost elements. However, the results of El-Haram and Horner (2002) and Meng et al. (2009) illustrated that of those only the five factors: lifetime, plan shape, GFA, storey heights and the total height of the building influence the said cost elements. Despite, Ali et al. (2010) stated that the external work cost was affected by the size of the building (GFA), while the current study results reflected that the cost of external work is not affected by the size of the building (GFA). Furthermore, the current study further concludes that GFA is directly affecting the cleaning cost and fabric cost.

According to Cunningham (2013), all five factors under the nature of the site were affecting the construction and maintenance cost. The participants of the current study were also of similar observations. However, Kerama (2013) stated that the availability of resources has an impact on the utility, decoration, and cleaning costs of a building. However, this was not something that can be concluded from the current study.

Table 3 shows that all four sub-factors of the technical factor influence the services management, construction, repairs and replacement and maintenance management costs. This result is in line with the result of Kerama (2013), Meng et al. (2009) and Bari et al. (2012). Furthermore, though Ali et al. (2010) identified that the decoration cost was affected by the factors such as technology used, workmanship and durability of materials and equipment used, survey results only identified the quality of materials and equipment used. Survey findings pointed out that the technology used, workmanship, and quality of materials and equipment used to affect the fabric cost.

The factor, expectation of tenant affects all the LCC elements as per the survey findings. The results of Meng et al. (2009), Cunningham (2013), and Che-Ghani et al. (2016) coincide with this finding. However, there is no relationship identified between this factor and utility and services management cost through literature. According to Kerama (2013), factors such as the expectation of the tenant and use of the property were affecting the administration cost. This finding was similar to the current study findings. Though the literature findings (Table 1) revealed that delay and failures in reporting problems affected the decoration fabric cost, it was not reflected via the survey findings.

The findings of Kerama (2013), Ali et al. (2010), and Cunningham (2013) revealed that the factor of; number of occupants affects the utility, administration, services management, repair and replacement and maintenance management costs. The survey result also complies with the above findings. However, survey results further identified that the construction, cleaning, and external costs also affected by this factor. Though the survey findings revealed that the administration cost was influenced by the legislative constraints, Krstić and Marenjak (2012) identified it as a non-affected factor to the administration cost. 


\section{Conclusions}

From the study, it can be concluded that the thirteen (13) factors such as plan shape, size of the building, number of occupants, function of the building, quality of material and equipment used, physical condition, the technology used, the durability of material and equipment used, lifetime, location, workmanship, and legislative constraints highly affect the LCC of a building. Analysis results further concluded that all 24 factors influence the construction and maintenance management cost elements at different significant levels. Out of them, size of the building is the highly influencing factor of the construction cost. Moreover, the function of the building can be considered as a highly influencing factor among the identified factors to the most of LCC elements including utility, administration, services management, cleaning, external work, and maintenance management. Decoration cost is mainly affected by the aesthetic appearance of the building. Aesthetical appearance highly influences the fabric cost of the building. The technology used is highly affecting the cleaning cost. The results of this study provide a detailed description of the factors that affect the LCC of a building and their significance levels. It is recommended that cost practitioners should give due consideration to those factors which are identified as highly influencing the LCC and to optimise the LCC of a building during its early life cycle phase. Hence, it will assist the cost practitioners to make the precise decision through LCC planning.

\section{References}

Ali, A., Kamaruzzaman, S., Sulaiman, R., \& Peng, C. Y. 2010. Factors Affecting Housing Maintenance Cost in Malaysia. Journal of Facilities Management, 8(4), p. 285-298.

Aye, L., Bamford, N., Charters, B., \& Robinson, J. 2000. Environmentally Sustainable Development: A LifeCycle Costing Approach for A Commercial Office Building in Melbourne, Australia. Construction Management and Economics, 18(8), p. 927-934.

Bari, N. A., Yusuff, R., Ismail, N., Jaapar, A., \& Ahmad, R. 2012. Factors Influencing the Construction Cost of Industrialised Building System (IBS) Projects, Social and Behavioral Sciences. 35, p. 689-696.

Che-Ghani, N. Z., Myeda, N. E., \& Ali, A. S. 2016. Operations and Maintenance Cost for Stratified Buildings: A Critical Review. MATEC Web of Conferences, 66.

Cunningham, T. 2013. Factors Affecting the Cost of Building Work-An Overview. Dublin Institute of Technology.

El-Haram, M. A., \& Horner, M. W. 2002. Factors Affecting Housing Maintenance Cost. Journal of Quality in Maintenance Engineering, 8(2), p. 115-123.

Fuller, S. 2016. Life-Cycle Cost Analysis (LCCA). National Institute of Standards and Technology (NIST).

Gluch, P., \& Baumann, H. 2004. The Life Cycle Costing (LCC) Approach: A Conceptual Discussion of Its Usefulness for Environmental Decision-Making. Building and Environment, 39(5), p. 571-580.

Henn, C. L. 2002. The New Economics of Life Cycle Thinking. Proceedings of the 1993 IEEE International Symposium on Electronics and the Environment. Arlington, VA, USA: IEEE.

Heralova, R. S. 2018. Importance of Life Cycle Costing for Construction Projects. Engineering for Rural Development, 23, p. 1223-1227.

Islam, H., Jollands, M., \& Setunge, S. 2015. Life Cycle Assessment and Life Cycle Cost Implication of Residential Buildings-A Review. Renewable and Sustainable Energy Reviews, 42, p. 129-140.

ISO ISO.15686. 2008. Buildings and Constructed Assets, Service Life Planning. Part 5. Geneva: International Standards Organisation.

Kerama, N. S. 2013. Factors Affecting Housing Maintenance Management Cost in Kakamega Municipality.

Kinlan, D. 2014. Adverse Physical Conditions \& The Experienced Contractor (1st ed.).

Kneifel, J. 2010. Life-Cycle Carbon and Cost Analysis of Energy Efficiency Measures In New Commercial Buildings. Energy and Buildings, 42(3), p. 333-340.

Korpi, E., \& Ala-Risku, T. 2008. Life Cycle Costing: A Review of Published Case Studies. Managerial Auditing Journal, 23(3), p. 240-261.

Krstić, H., \& Marenjak, S. 2012. Analysis of Buildings Operation and Maintenance Costs. Građevinar, 64(4), p. 293-303.

Meng, X., Wang, L., \& Currit, N. 2009. Morphology-Based Building Detection from Airborne Lidar Data. Photogrammetric Engineering \& Remote Sensing, 75(4), p. 437-442.

Morrissey, j., \& Horne, R. 2011. Life Cycle Cost Implications of Energy Efficiency Measures in New Residential Buildings. Energy and Buildings, 43(4), p. 915-924.

Norris, G. A. 2001. Integrating Life Cycle Cost Analysis And LCA. The International Journal of Life Cycle Assessment, 6, p. 118-120. 
Schade, J. 2014. Life Cycle Cost Calculation Models for Buildings. Lulea University of Technology.

Shabniya, V. 2017. Factors Affecting Construction Cost Estimation of Building Projects. International Journal of Recent Trends in Engineering and Research, 3(4), p. 379-387.

Sterner, E. 2002. Green Procurement of Buildings: Estimation of Life Cycle Cost and Environmental Impact. $\mathrm{PhD}$ Thesis.

Wen, Y. K., \& Kang, Y. J. 2001. Minimum Building Life-Cycle Cost Design Criteria. I: Methodology. Journal of Structural Engineering, 127, p. 330-337.

Zareaian, S., \& Zadeh, K. A. 2013. The Role of Climate Factors on Designing and Constructing Buildings (From Urbanization Architecture Approach). Bulletin of Environment, Pharmacology and Life Sciences, 3(1), p. $197-200$. 